\title{
P0125
}

\section{AN INVESTIGATION OF A19 LED RETROFIT LAMPS IN THE TURKISH MARKET}

\author{
Cemre Köseoğlu et al.
}

DOI 10.25039/x46.2019.PO125

from

CIE x046:2019

\section{Proceedings}

of the

29th CIE SESSION

Washington D.C., USA, June 14 - 22, 2019

(DOI 10.25039/x46.2019)

The paper has been presented at the 29th CIE Session, Washington D.C., USA, June 14-22, 2019. It has not been peer-reviewed by CIE.

(C) CIE 2019

All rights reserved. Unless otherwise specified, no part of this publication may be reproduced or utilized in any form or by any means, electronic or mechanical, including photocopying and microfilm, without permission in writing from CIE Central Bureau at the address below. Any mention of organizations or products does not imply endorsement by the CIE.

This paper is made available open access for individual use. However, in all other cases all rights are reserved unless explicit permission is sought from and given by the CIE.

CIE Central Bureau

Babenbergerstrasse 9

A-1010 Vienna

Austria

Tel.: +4317143187

e-mail: ciecb@cie.co.at

www.cie.co.at 


\title{
AN INVESTIGATION OF A19 LED RETROFIT LAMPS IN THE TURKISH MARKET
}

\author{
Köseoğlu, C. ${ }^{1}$, Erdem Atılgan, L. ${ }^{1}$ \\ ${ }^{1}$ Istanbul Technical University, Electrical Engineering Department, Istanbul, TURKEY \\ erdeml@itu.edu.tr
}

DOI 10.25039/x46.2019.PO125

\begin{abstract}
The Turkish LED market receives from a significant number of different brands, providing the end user with similar retrofit lamps easily purchasable from different shopping channels. This variety in products results in a broad quality spectrum among LED light sources. This study aims at evaluating off the shelf A19 LED retrofit lamps in the Turkish market as of November 2018 through electrical, photometric, spectral and temporal measurements. In order to do this, 50 different A19 type E27 base LED retrofits have been analysed. The rated values of the LED retrofits have been compared to the values obtained through measurements and the results have been analysed according to the relative differences between the rated and measured results as well as values defined by European standards. The main objective of the study is to evaluate the properties of LED retrofits consumers frequently buy and utilize in their interior lighting environments.
\end{abstract}

Keywords: Lighting, LED (Light Emitting Diode), LED Retrofit, Energy Efficiency

\section{Introduction}

Light Emitting Diode (LED) technology has become an important tool for energy savings and is utilized in all lighting areas, most importantly in general lighting. The phase out of inefficient light bulbs by the European Union (EU) was followed by Turkey, which increased the demand for more efficient alternatives, directing users to the purchase of LED retrofits. The Turkish LED market receives from a significant number of different brands, providing the end user with similar retrofit lamps easily purchasable from different shopping channels. This variety in products results in a broad quality spectrum among LED light sources. The differences in quality are mainly related to luminous flux, colour temperature, lifetime and the occurrence of catastrophic failures. The product information is usually limited to the packages of the lamps and most of the time deficient, especially for low price products, and this fact reduces the confidence of the end user in these products (European Commission, 2010, European Commission, 2011). Examples in the literature show that LEDs the large variety in electrical, thermal and photometric properties in LEDs is not specific to Turkey and that the rated operating conditions and actual working conditions of these light sources are contradictory most of the time (Sun et al., 2015, Hong Kong Consumer Council, 2017, De Santi et al, 2015).

Turkey, as a member of the Customs Union as well as a candidate for the European Union (EU) membership adopts EU Regulations, obligating the CE mark for the import and sale of LED retrofit lamps in the Turkish market. The Turkish Standards Institute makes detailed inspection s of the conformity of LED lamps entering the Turkish customs, however, the inspections are on a sample of the products provided by the importing company and may not be representative of the entire population. The after-market monitoring system then removes the unsatisfactory products from the market if and when there are customer complaints and through random selection and testing. Within this context, this study aims at evaluating off the shelf A19 LED retrofit lamps in the Turkish market as of November 2018 through electrical, photometric, spectral and temporal measurements. In order to do this, 50 different A19 type E27 base LED retrofits have been selected. In selecting the retrofits, the major approach has been to choose retrofits which are readily available at easy access purchase channels such as supermarkets, hardware stores and popular online shopping stores. The purchase price per retrofit has been kept under 20 Turkish Liras. The main objective of the study is to evaluate the properties of LED retrofits which consumers frequently buy and utilize in their interior lighting environments. 


\section{Measurement Methods}

The retrofits used in the study are non-dimmable frosted A19 lamps with E27 lamp bases. Using the values given on the lamp packages as rated values if and when available, luminous flux, power, current, voltage, frequency, power factor, lifetime, number of switching cycles, energy efficiency class, correlated colour temperature (CCT), colour rendering index (CRI), minimum operating temperature, maximum operating temperature, mercury content, relative humidity, lamp size and the light distribution angle values have been recorded for comparison to the results which will be obtained from the measurements. Following the documentation of all available information, the luminous flux, power, current, voltage, frequency, power factor, total harmonic distortion, correlated colour temperature (CCT), colour rendering index (CRI), colour fidelity and colour gamut according to IES TM 30-15, flicker index, percentage flicker and SVM values have been measured for each retrofit. In addition to the measurements, efficacy and energy efficiency index calculations have been performed. For the luminous flux measurements Everfine $1 \mathrm{~m}$ diameter Integrating Sphere and for the electrical measurements, Everfine PF9811 digital power meter have been used. For spectral properties Everfine SPIC 200 model spectrometer and for flicker measurements UPRTek $350 \mathrm{~N}$ hand held spectrometer have been utilized. Figure 1 shows the general experimental setup in the dark room of Istanbul Technical University, Electrical Engineering Department and Figure 2 shows a sample retrofit that has been utilized in the study. The measurements were carried out according to IES LM-79-08; the retrofits were initially stabilized through measurements of luminous flux and power to maintain a variation less than $0.5 \%$ for at least 3 readings over a period of 30 minutes taken 15 minutes apart. The stabilization periods have also been recorded for each retrofit (IES, 2008).

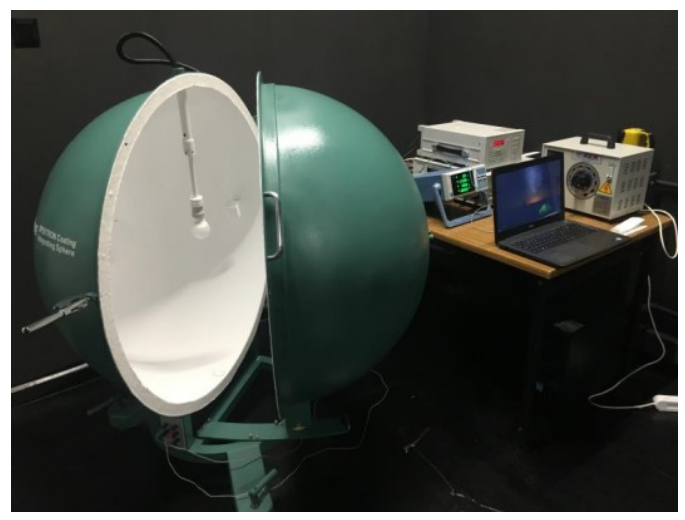

Figure 1 - Experimental Setup

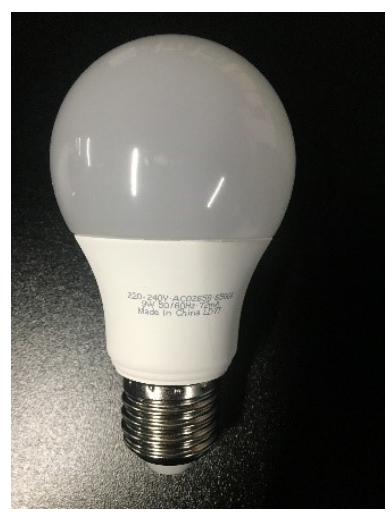

Figure 2 - Example LED Retrofit

\section{Measurement Results and Evaluations}

The results obtained from the measurements are analysed in three separate sections; electrical and photometric, spectral and temporal results. The values obtained from the measurements are compared to the rated values from the boxes of the retrofits and discussed in terms of current standards. Due to the large number of retrofits and thus measurements, the results that show a significant difference in comparison to rated values are reported along with problematic values in comparison to values defined by standards. In rated value vs. measured value comparisons, a relative difference higher than $10 \%$ has been taken as a significant difference.

\subsection{Electrical and Photometric Results}

\subsubsection{Luminous Flux, Power, Efficacy and Energy Efficiency Index}

Table 1 shows the stabilization time $t_{\mathrm{s}}$, rated power consumption $P_{0}$, measured power consumption $P_{1}$, relative difference between the rated and measured power values $\Delta P$, rated luminous flux $\Phi_{0}$, measured luminous flux $\Phi_{l}$, relative difference between the rated and measured luminous flux values $\Delta \Phi$, efficacy calculated using the rated luminous flux and power values $e_{0}$, efficacy calculated using the measured luminous flux and power values $e_{1}$, the relative difference between these two efficacy values $\Delta e$ according to the sample number (\#). 
Grey values in the table are marked for retrofits where the difference between the expected and measured values is greater than $10 \%$.

Table 1 - Electrical Measurements and Comparisons

\begin{tabular}{|c|c|c|c|c|c|c|c|c|c|c|}
\hline \# & $t_{\mathrm{s}}[\mathrm{m}]$ & $P_{0}[\mathrm{~W}]$ & $P_{1}[\mathrm{~W}]$ & $\Delta P[\%]$ & $\Phi_{0}[\mathrm{Im}]$ & $\Phi_{1}[\mathrm{Im}]$ & $\begin{array}{l}\Delta \Phi \\
{[\%]}\end{array}$ & $\begin{array}{c}e_{0} \\
{[\mathrm{~lm} / \mathrm{W}]}\end{array}$ & $\begin{array}{c}e_{1} \\
{[\mathrm{~m} / \mathrm{W}]}\end{array}$ & $\Delta e[\%]$ \\
\hline 5 & 55 & 9,0 & 9,48 & 5,33 & 850 & 803,8 & $-5,4$ & 94,4 & 84,8 & $-10,2$ \\
\hline 8 & 50 & 9,0 & 9,62 & 6,89 & 800 & 762,2 & $-4,7$ & 88,9 & 79,2 & $-10,9$ \\
\hline 10 & 55 & 8,0 & 9,19 & 14,88 & 680 & 764,0 & 12,3 & 85,0 & 83,1 & $-2,2$ \\
\hline 13 & 50 & 6,0 & 5,94 & $-1,00$ & 490 & 571,9 & 16,7 & 81,7 & 96,3 & 17,9 \\
\hline 15 & 55 & 10,0 & 9,03 & $-9,70$ & 910 & 871,2 & $-4,3$ & 91,0 & 107,6 & 18,3 \\
\hline 16 & 65 & 7,6 & 7,25 & $-4,61$ & 806 & 780,4 & $-3,2$ & 106,1 & 86,0 & $-18,9$ \\
\hline 18 & 60 & 5,8 & 5,6 & $-3,45$ & 470 & 568,2 & 20,9 & 81,0 & 101,5 & 25,2 \\
\hline 22 & 55 & 9,0 & 9,14 & 1,56 & 810 & 1038,3 & 28,2 & 90,0 & 113,6 & 26,2 \\
\hline 24 & 55 & 10,0 & 8,54 & $-14,60$ & 850 & 846,0 & $-0,5$ & 85,0 & 99,1 & 16,5 \\
\hline 25 & 65 & 10,0 & 8,46 & $-15,40$ & 810 & 774,9 & $-4,3$ & 81,0 & 91,6 & 13,1 \\
\hline 27 & 55 & 9,0 & 4,56 & $-49,33$ & 720 & 218,9 & $-69,6$ & 80,0 & 48,0 & $-40,0$ \\
\hline 29 & 45 & 9,0 & 6,74 & $-25,11$ & 630 & 377,9 & $-40,0$ & 70,0 & 56,1 & $-19,9$ \\
\hline 31 & 45 & 10,0 & 8,22 & $-17,80$ & 1000 & 610,6 & $-38,9$ & 100,0 & 74,3 & $-25,7$ \\
\hline 32 & 50 & 9,0 & 5,98 & $-33,56$ & 530 & 360,3 & $-32,0$ & 58,9 & 60,2 & 2,3 \\
\hline 33 & 70 & 11,0 & 10,18 & $-7,45$ & 990 & 1044,7 & 5,5 & 90,0 & 102,6 & 14,0 \\
\hline 34 & 75 & 11,0 & 10,36 & $-5,82$ & 990 & 884,2 & $-10,7$ & 90,0 & 85,3 & $-5,2$ \\
\hline 35 & 50 & 7,0 & 3,61 & $-48,43$ & 420 & 242,4 & $-42,3$ & 60,0 & 67,1 & 11,9 \\
\hline 36 & 45 & 7,0 & 4,74 & $-32,29$ & 385 & 319,8 & $-16,9$ & 55,0 & 67,5 & 22,7 \\
\hline 37 & 75 & 8,0 & 7,79 & $-2,63$ & 700 & 825,5 & 17,9 & 87,5 & 106,0 & 21,1 \\
\hline 38 & 130 & 9,0 & 6,31 & $-29,89$ & - & 281,3 & - & - & 44,6 & - \\
\hline 42 & 35 & 9,0 & 8,73 & $-3,00$ & 900 & 647,3 & $-28,1$ & 100,0 & 74,2 & $-25,8$ \\
\hline 43 & 45 & 9,0 & 3,56 & $-60,44$ & - & 236,7 & - & - & 66,5 & - \\
\hline 44 & 45 & 12,0 & 5,33 & $-55,58$ & 900 & 394,8 & $-56,1$ & 75,0 & 74,1 & $-1,2$ \\
\hline 45 & 50 & 9,0 & 3,5 & $-61,11$ & - & 158,6 & - & - & 45,3 & - \\
\hline 47 & 50 & 9,0 & 5,45 & $-39,44$ & - & 284,3 & - & - & 52,2 & - \\
\hline 48 & 45 & 9,0 & 6,62 & $-26,44$ & 350 & 514,3 & 46,9 & 38,9 & 77,7 & 99,8 \\
\hline 49 & 80 & 9,0 & 5,19 & $-42,33$ & 650 & 326,5 & $-49,8$ & 72,2 & 62,9 & $-12,9$ \\
\hline 50 & 55 & 9,0 & 6,38 & $-29,11$ & - & 438,5 & - & - & 68,7 & - \\
\hline
\end{tabular}

When the power consumption was examined, it was observed that 17 of the retrofits have more than $10 \%$ difference between the rated and measured values. Only one of these 17 retrofits consumes more power from grid than the value specified in the package, 9,19 W compared to the rated value of $8 \mathrm{~W}$. The largest difference is experienced with Retrofit \#45 with a relative difference of $61,11 \%$; the package information claims a power value of $9 \mathrm{~W}$ while the actual energy consumption is only $3,5 \mathrm{~W}$. For luminous flux, the largest difference is seen in retrofit \#27 with -69,6\%; the rated flux is $720 \mathrm{Im}$ while the measured flux is $218,9 \mathrm{Im}$, an unacceptable difference in terms of light output. Here, 6 retrofits show values above rated luminous flux values, while 10 retrofits fall short of their rated light outputs. Among the retrofits that were analysed in this study, the efficacy values were not rated, therefore the values presented in 
Table 1 were calculated using the rated power and luminous flux values and compared to the values obtained from the measurements. As can be expected, the differences in power and luminous flux values translated into differences in efficacy values as well. The largest difference is experienced with retrofit \#48; for this retrofit, the relative difference in power is $-26,44 \%$ while the relative difference in luminous flux is 46,9 percent, the resulting efficacy value being $99,8 \%$ higher than expected. In total, 18 retrofits show significant differences from expected efficacy values.

To take a look at the entire population of relative differences for power, luminous flux and efficacy, Figure 3 gives box plots of the values for all 50 retrofits. Here, the respective average and median values are $-12,31 \%$ and $-4,19 \%$ for power; $-6,1 \%$ and $-2,1 \%$ for luminous flux and $2,93 \%$ and $1,51 \%$ for efficacy. The previously mentioned high differences can be seen in the box plots as outliers.

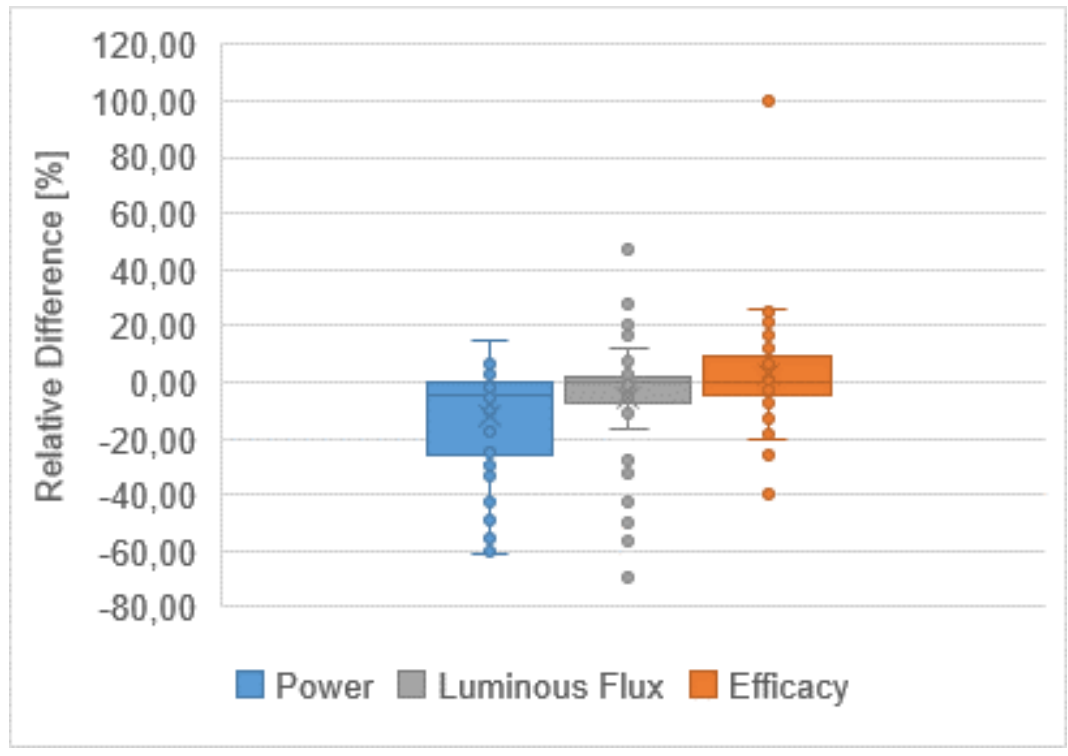

Figure 3 - Box Plot for Relative Differences in Power, Luminous Flux and Efficacy for all retrofits

While efficacy ratings were unavailable, the energy efficiency classes were available for 47 out of 50 of the retrofits, $7 \mathrm{~A}$ class, $35 \mathrm{~A}+$ class, $4 \mathrm{~A}++$ class and 1 claiming to be $\mathrm{A}+$ and $\mathrm{A}++$ at the same time. A simple calculation of energy efficiency index according to EU Regulation $874 / 2012$ using the measured power and luminous flux values showed that 9 retrofits were one class below their rated energy class and 3 were actually above their rated energy class (European Commission, 2012a, Yurtseven, 2016).

Looking at the results, it can be seen that 17 retrofits in power values, 16 retrofits in luminous flux values and 18 retrofits in efficacy values show significant differences in terms of rated vs. measured and calculated numbers. This translates into problems in approximately $34 \%$ of the analysed retrofits, constituting an important problem for the end user who buys a certain product for its rated power or luminous flux value and ends up with a different result than expected.

\subsubsection{Power Factor and Total Harmonic Distortion}

Power Factor and Total Harmonic Distortion (THD) are two very important electrical properties that maintain grid quality. The Electromagnetic Compatibility (EMC) standard IEC 61000-3-22014 defines the limits of current total harmonic distortion (THDc) for lighting equipment above $25 \mathrm{~W}$, however, the standard does not specify a limit for systems below $25 \mathrm{~W}$, thus the retrofits analysed in this study are not subjected to this standard in terms of THDc (IEC, 2014). The American Standard ANSI C82.77-10 on the other hand requests a maximum $\mathrm{THD}_{\mathrm{c}}$ of 20 (Djuretic et al., 2019). Among the measured retrofits, there is only 1 that adheres to the ANSI standard, retrofit \#22 with a THDc value of 15,4. Of the remaining retrofits, 32 lamps have THDc values above $100 \%$, the highest reaching $148,6 \%$. The remaining 17 retrofits have THD $_{c}$ values ranging between $24,4-58 \%$. 
According to the Directional Lamps, Light-emitting Diode Lamps and Related Equipment Directives published by the European Union (EU) under the Eco-design regulation, no power factor is specified for lamps below $2 \mathrm{~W}$. For power values between $2 \mathrm{~W}$ and $5 \mathrm{~W}$, the power factor must be higher than 0,4 , between $5 \mathrm{~W}$ and $25 \mathrm{~W}$, higher than 0,5 and for values above $25 \mathrm{~W}$, the power factor must be higher than 0,9 (European Commission, 2012b). The retrofits analysed in the study have power consumption values between 3,5 and $10,1 \mathrm{~W}$ corresponding to 0,4 and 0,5 for power factor values. The measurement results show that unfortunately 14 out of 50 lamps do not provide the values specified by the EU.

\subsection{Spectral Results}

Table 2 gives the rated and measured values for colour rendering index $R_{a} 0$ and $R_{a} 1$, IES TM 3015 colour rendering metrics colour fidelity $R_{\mathrm{f}}$ and colour gamut $R_{\mathrm{g}}$ (IES, 2015), rated relative colour temperature $C C T_{0}$, measured relative colour temperature $C C T_{1}$ and the relative difference between these values $\triangle C C T$. For the colour rendering index, the relative difference has not been calculated since most of the $R_{a}$ values are not specified on the package or either are expressed as greater than a certain value when they are specified.

Table 2 - Spectral Measurements and Comparisons

\begin{tabular}{|c|c|c|c|c|c|c|c|}
\hline$\#$ & $R \mathrm{a}_{0}$ & $R \mathrm{a}_{1}$ & $R_{\mathrm{f}}$ & $R_{\mathrm{g}}$ & $C C T_{0}[\mathrm{~K}]$ & $C C T_{1}[\mathrm{~K}]$ & $\Delta C C T[\%]$ \\
\hline 3 & - & 78,9 & 81,2 & 93,4 & 2700 & 2986 & 10,6 \\
\hline 5 & - & 82,9 & 81,6 & 92,2 & 2700 & 2995 & 10,9 \\
\hline 6 & 80 & 87,7 & 82 & 92,4 & 6500 & 7829 & 20,4 \\
\hline 15 & $>80$ & 71,3 & 72,3 & 92,7 & 2700 & 2982 & 10,4 \\
\hline 27 & - & 79,9 & 74,9 & 92,1 & 6400 & 8581 & 34,1 \\
\hline 29 & $>70$ & 77,5 & 72 & 95 & 6500 & 7963 & 22,5 \\
\hline 38 & - & 79,5 & 71,2 & 96,3 & 7000 & 8879 & 26,8 \\
\hline 39 & - & 68 & 70 & 88,9 & 2700 & 2999 & 11,1 \\
\hline 44 & - & 68,2 & 63,6 & 95,4 & 6500 & 7147 & 10,0 \\
\hline 50 & - & 69,7 & 68,2 & 92,9 & 2700 & 4264 & 57,9 \\
\hline
\end{tabular}

The results show that 3 retrofits fall short of the minimum colour rendering index for indoor lighting according to IEC $12464-1$ of 70 , while 1 has a measured value below the rated value (IEC, 2011). $R_{\mathrm{f}}$ and $R_{\mathrm{g}}$ values are important on the basis of application; low $R_{\mathrm{f}}$ values also correspond to low $R_{\mathrm{a}}$ values. All $R_{\mathrm{g}}$ values are below 100 , suggesting that with all the retrofits in hand, colours would appear less saturated compared to a reference light source. For correlated colour temperature (CCT) values, the comparisons between the rated and measured results show that 9 retrofits have differences of $10 \%$ and above. The highest difference is experienced with retrofit \#50, where the rated CCT is $2700 \mathrm{~K}$ and the measured CCT is 4264 $\mathrm{K}$. The authors believe that the highest user dissatisfaction would be experienced with retrofits \#27 and \#38 where the measured CCT values go above $8500 \mathrm{~K}$, resulting in a much cooler white light than expected.

\subsection{Temporal Results}

Visual perception effects such as flicker, stroboscopic effect and the phantom array effect are known as temporal light artefacts (Veitch 2018). The CIE Technical Note 006-2016 defines flicker as "perception of visual unsteadiness induced by a light stimulus the luminance or spectral distribution of which fluctuates with time, for a static observer in a static environment" (CIE, 2016). Currently, three common metrics are utilized for the quantification of this perception, namely the Flicker Index defined by IESNA, the percent flicker value, defined again by IESNA (IESNA, 2000) and finally the stroboscopic effect visibility measure (SVM) proposed by Perz and his colleagues (Perz et al., 2015). IESNA recommends the flicker index value to be lower than 0,1 for good lighting quality. The percent flicker value on the other hand is a relative value, giving the maximum luminance decrease compared to the peak luminance value and as this value increases, flicker also increases. The SVM on the other hand quantifies the visibility of the stroboscopic effect, as its name implies. The SVM value is evaluated as greater 
than 1 , equal to 1 and less than 1, translating into a visible stroboscopic effect with a probability of 0,5 or more, stroboscopic effect at the visibility threshold and stroboscopic effect that is not visible with a probability less than 0,5 , respectively.

In Table 3, the measured flicker percentage, flicker index, stroboscopic effect visibility measure (SVM) values that are above the specified limits are reported. The percentage flicker values above $50 \%$, flicker index values above 0,1 and SVM values above 1 have been marked with grey in the Table.

Table 3 - Temporal Measurements

\begin{tabular}{|c|c|c|c|}
\hline$\#$ & $\%$ Flicker & Flicker index & SVM \\
\hline 7 & 99,093 & 0,501 & 5,200 \\
\hline 13 & 31,968 & 0,086 & 1,047 \\
\hline 19 & 88,240 & 0,040 & 0,020 \\
\hline 21 & 53,400 & 0,156 & 1,903 \\
\hline 22 & 35,939 & 0,108 & 1,313 \\
\hline 28 & 0,366 & 0,110 & 1,326 \\
\hline 32 & 59,032 & 0,163 & 1,965 \\
\hline 36 & 75,114 & 0,212 & 2,568 \\
\hline 37 & 30,953 & 0,091 & 1,116 \\
\hline 48 & 83,626 & 0,255 & 3,071 \\
\hline 49 & 70,561 & 0,202 & 2,446 \\
\hline 50 & 91,926 & 0,270 & 3,226 \\
\hline
\end{tabular}

According to the measurements, 8 retrofits present with percentage flicker values that are above $50 \%$. With flicker index values, 9 retrofits are above the IESNA recommended flicker index value of 0,1 . Finally, the SVM values show that 11 retrofits have values above 1 . As can be seen from the Table, the results for these three different metrics are quite consistent with each other; the usual presentation is that all flicker metrics show problems for these retrofits. On the other hand, retrofit \#19 for example shows a high flicker percentage of 88,2 but good flicker index SVM values. While current flicker metrics only correspond to high quality lighting recommendations, the measurement results show that especially with high SVM values such as 5,2 experienced in retrofit \#7 could result in both user dissatisfaction and even safety hazards when these light sources are used in work areas equipped with objects which have moving parts.

\section{Conclusion}

This study aimed at analysing a variety of different LED A19 retrofit lamps available in the Turkish market. In order to do this, 50 retrofits were evaluated through measurements regarding electrical, photometric, spectral and temporal properties. The results have been assessed in terms of significant differences between rated and measured values and those values with relative differences above $10 \%$ have been reported. In addition to the comparisons of rated and measured values, conformity to current standards have also been investigated. Examined results show that the majority of the lamps adhere to the rated values given on their packages. However, important differences have been spotted for a significant number of lamps, especially in terms of luminous flux, power, expected efficacy, CRI and CCT values which are very important attributes for lighting quality.

In terms of power, luminous flux and efficacy, approximately one third of the lamps showed significantly different results compared to their rated values. Among electrical properties, the current THD values are not regulated by the European Standard as the retrofits had power values below $25 \mathrm{~W}$; this resulted in quite high values of current THD. The power factor values of $28 \%$ of the lamps on the other hand was unsatisfactory. Spectral measurements showed 3 
lamps below the necessary color rendering index of 70 and 3 retrofits showed major differences in rated and measured CCT values. In terms of temporal properties, when the flicker percentage, flicker index and stroboscopic effect visibility measure (SVM) values obtained from the measurements are examined, common problems were encountered for approximately $20 \%$ of the retrofits.

Overall, the results indicate that while the majority of these commonly used light sources adhere to their rated values and standards, there's still an important percentage of light sources that do not. Most of the quantities evaluated in the study are beyond the average customer's knowledge; this fact indicates that steps should be taken to make the after-market monitoring for LED retrofit lamps much stricter. The Turkish Standards Institute has already taken comprehensive measures to increase the reliability of the lighting products entering the Turkish market, however, as it is impossible to monitor every single product, a stricter regulation of the after-market monitoring as well as greater sanctions on manufacturers that do not adhere to the standards and regulations must be established in order to increase the quality of the available products. The elimination of defected products will most definitely ameliorate lighting quality and energy efficiency while maintaining a better experience for the end user at the same time. This study will be carried out further with long term measurements to elaborate the ongoing performance of the analysed retrofits.

\section{Acknowledgements}

This study has been supported by the Istanbul Technical University Scientific Research Unit Project MAB-2018-41220, "The Analysis of Electrical, Thermal and Photometric Properties of LED Retrofits in the Turkish Market".

\section{References}

CIE, 2016. CIE TN 006-2016. Visual Aspects of Time-Modulated Lighting Systems - Definitions and Measurement Models. Vienna, Austria: CIE.

DE SANTI, C., DAL LAGO, M., BUFFOLO, M., MONTI, D., MENEGHINI, M., MENEGHESSO, G., ZANONI, E. 2015. Failure Causes and Mechanisms of Retrofit LED Lamps. Microelectronics Reliability, 55, Issues 9-10, 1765-1769.

EUROPEAN COMMISSION 2010. Photonics Unit, Photonics Technologies and Markets for a Low Carbon Economy - Summary Report. SMART 2010/0066.

EUROPEAN COMMISSION 2011. Green Paper: Lighting the Future - Accelerating the Deployment of Innovative Lighting Technologies COM (2011) 889 Final. 15/12/2011 Brussels.

EUROPEAN COMMISSION 2012a. Commission Delegated Regulation No 874/2012 of 12 July 2012 supplementing Directive 2010/30/EU of the European Parliament and of the Council with regard to energy labelling of electrical lamps and luminaires. Official Journal L258, 26/09/2012, p. 01-20.

EUROPEAN COMMISSION 2012b. Commission Regulation (EU) No 1194/2012 of 12 December 2012 implementing Directive 2009/125/EC of the European Parliament and of the Council with regard to ecodesign requirements for directional lamps, light emitting diode lamps and related equipment. Official Journal L342, 14/12/2012, p. 0206-0227.

HONG KONG CONSUMER COUNCIL 2017. LED Light Bulbs Vary Greatly in Energy Saving Performance - CHOICE \#466. [online] Available at https://www.consumer.org.hk/ws_en/news/press/p46601.html [Accessed 20 November 2017].

IEC 2011. IEC 12464-1:2011 Light and Lighting - Lighting of Work Places - Part 1: Indoor Work Places.

IEC 2014. IEC 61000-3-2:2014 Electromagnetic Compatibility (EMC) - Part 3-2: Limits - Limits for Harmonic Current Emissions (Equipment Input Current $\leq 16$ A per phase). 
IES 2018. IES LM-79-08. IES Approved Method for the Electrical and Photometric Measurements of Solid-State Lighting Products. USA: Illuminating Engineering Society.

IES 2015. TM-30-15 IES Method for Evaluating Light Source Color Rendition. New York: Illuminating Engineering Society.

IESNA 2000. IESNA Lighting Handbook. Edited by Mark Stanley Rea. 9th edition. New York, NY: Illuminating Engineering Society.

PERZ, M., VOGELS, I.M.L.C., SEKULOVSKI, D., WANG, L., TU, Y., HEYNDERICKX, I.E.J. 2015. Modeling the Visibility of the Stroboscopic Effect Occurring in Temporally Modulated Light Systems. Lighting Research and Technology, 47: 281-300.

SUN, L., ZHU, J., WONG, H. 2015. Simulation and Evaluation of the Peak Temperature in LED Light Bulb Heatsink. Microelectronics Reliability, 61, 140-144.

VEITCH, J. A., MARTINSONS, C. 2018. Visual Perception under Energy-Efficient Light Sources - Detection of the Stroboscopic Effect Under Low Levels of SVM. IEA 4E Solid State Lighting Annex Interim Report.

YURTSEVEN B., ERDEM ATILGAN, L. 2016. Energy Labelling of Electrical Lamps and Luminaires in the Scope of Ecodesign. SBE16 - Smart Metropoles - Integrated Solutions for Sustainable and Smart Buildings \& Cities. 401-409, Istanbul, Turkey. 